Anuario Latinoamericano Ciencias Políticas y Relaciones Internacionales vol. 1, 2014

p. $143-154$

\title{
Muros y vallas contra la sociedad de bienestar
}

\author{
Aneta de la Mar Ikonómova \\ UNIVERSIDAD EXTERNADO DE COLOMBIA, \\ BOGOTÁ \\ anetadelamar@yahoo.com
}

\begin{abstract}
RESUMEN
Nunca en la historia del mundo se han creado tantos muros y vallas para impedir que la gente cruce libremente espacios nacionales, internacionales, sociales, económicos, étnicos y culturales con propósitos de buscar oportunidades y alcanzar la vida de la sociedad del bienestar. Estas murallas, vallas, barreras, cercas y fronteras fortificadas muchas veces son consideras los nuevos muros de la globalización. Es difícil no ver la gran paradoja del nuevo contexto globalizado donde se promueve y defiende el derecho de la libre circulación de capitales $y$ finanzas $y$, a la vez, se cierran fronteras $y$ se hacen de ellas fortalezas para que "los incómodos" no crucen, no se integren a la sociedad de bienestar. ¿Son los muros de la globalización o son los límites de la globalización? Esta es la pregunta que se hacen muchos investigadores en los últimos años y éste es uno de los problemas que se va a tratar en esta ponencia.
\end{abstract}

PALABRAS CLAVE: globalización, fronteras, conflictos, migraciones.

\section{SUMMARY}

Never in the history of the world have been created so many walls and fences to prevent people from crossing national, international, social, economic, ethnic or cultural spaces with the purpose of seeking opportunities and achieving the life of the welfare society. Many consider these walls, fences, barriers or fortified borders as the new walls of the globalization. It is hard not to see the big paradox of the new globalized context that promotes and defends the right of free movement of capital and finances, but at the same time closes borders, so that "the uncomfortable" do not cross them and cannot get integrated into the welfare society. Are these the walls of the globalization or are they the limits of the globalization? This is the question asked by many researchers in the recent years and this is one of the problems that this paper will put into discussion.

KEYWORDS: globalization, borders, conflicts, migrations. 


\section{Introducción}

Nunca en la historia del mundo se han creado tantos muros y vallas para impedir que la gente cruce libremente espacios nacionales, internacionales, sociales, económicos, étnicos y culturales con propósitos de buscar oportunidades y alcanzar la vida de la sociedad del bienestar. Estas murallas, vallas, barreras, cercas y fronteras fortificadas muchas veces son consideras los nuevos muros de la globalización (Ortega 2006). Es difícil no ver la gran paradoja del nuevo contexto globalizado donde se promueve y defiende el derecho de la libre circulación de capitales y finanzas y, a la vez, se cierran fronteras y se hacen de ellas fortalezas, se construyen fosos, cercas y muros para que "los incómodos" no crucen, no se integren a la sociedad de bienestar. ¿Son los muros de la globalización o son los límites de la globalización? Esta es la pregunta que se hacen muchos investigadores en los últimos años y éste es uno de los problemas que se va a tratar en esta ponencia.

Étienne Balibar, igualmente como otros autores, cuestiona el sentido de la frontera y se pregunta cuál es su verdadera función hoy en día. “Toda reflexión sobre las relaciones entre la política y la mundialización nos coloca ante la posibilidad de un juego de palabras que nos remite a las diferentes acepciones de la palabra 'frontera' [...] La idea consistía en mostrar que las fronteras del Estado han llegado ya al límite histórico más allá del cual cumplen cada vez peor sus funciones internas y externas" (Balibar 2003: 165).

El muro es un tipo de frontera y, como dice Norberto Emmerich, "sabemos que hay distintos tipos de fronteras, algunas solo figuran en mapas y otras tienen muros de acero, en algunas la noción de nacionalidad es difusa y en otras constituye la categoría central de identificación. La historia ha conocido desde antiguo al muro como concreción física de una frontera" (Emmerich 2006). No obstante, el problema de las fronteras no es sólo un asunto de Estado, de defensa nacional y de identidad. En realidad, los muros y las vallas como fenómeno van más allá del paradigma de la globalización por estar tocando la misma base de la construcción de la sociedad moderna y su manera de considerar el mundo como dividido, fragmentado, convertido en mosaico de variadas propiedades.

\section{Primera imagen: el muro clásico del siglo $\mathrm{XX}$}

Plena guerra fría, 13 de agosto de 1961, la capital alemana amanece con un muro; la historia lo recordará como el Muro de Berlín. Se trata de una construcción de $120 \mathrm{~km}$, de 3,6 metros de altura; más adelante el muro fue reforzado con hormigón armado y la frontera entre los dos Berlines quedó protegida por una valla de tela metálica, cables de alarma, trincheras, cercas de alambre de púas, 300 torres de vigilancia y unos treinta bunkers. Funcionarios soviéticos y alemanes del Este querían salvar Alemania oriental de la amenaza del 
mundo capitalista, un enemigo bien visible y situado demasiado cerca, por lo tanto, los ideólogos del muro lo llamaron "Muro de Protección Antifascista". En la práctica su función quedó distinta - no permitir a los alemanes del Este huir del comunismo que se estableció en su territorio a partir de la llegada del Ejército Rojo al final de la Segunda Guerra Mundial. El muro fue hecho para producir miedo. Pero por tratarse de una frontera, era un límite fronterizo que podían cruzar sólo personas privilegiadas del régimen comunista. Para la mayoría de la gente de Europa Central y del Este, incluso yo, el Muro siempre simbolizó la era del encarcelamiento, la división de Europa y la humillación que el sistema comunista causaba negando los derechos de los ciudadanos de elegir libremente la forma de gobernarse y de circular.

La opinión pública occidental empezó a considerar este muro como el "muro de la vergüenza", por darse cuenta que Alemania del Este y Europa Oriental se convirtieron en un lugar donde no hay libertad y democracia sino sólo regímenes autoritarios. Sin embargo, nadie podía protestar abiertamente contra el nuevo muro que marcó la política bipolar de la época de postguerra. Tampoco nadie sabía cuándo se acabaría el juego de poderes entre las dos superpotencias - Estados Unidos y Unión Soviética.

Como todos muros, el Muro de Berlín no pudo existir para siempre: fue destruido por los propios alemanes que dijeron "no" a la falsa ingeniería política de la guerra fría. En la memorable noche del 9 de noviembre de 1989, los alemanes de los dos lados abrieron las puertas del muro y empezaron a demolerlo. Mucha gente por todo el mundo quedó conmovida, incluso, convencida de que nunca más se van a dar otras parecidas construcciones de prohibición e intimidación en nuestra sociedad contemporánea. Se pensaba que la vergüenza se había acabado y ya venía una época mejor de democracia y derechos humanos para todos ciudadanos y naciones.

Veinte años después de la caída del Muro de Berlín, se puede afirmar que no sólo nacieron nuevos muros, barreras, cercas, murallas, vallas y otros, sino que hoy por hoy parece normal que estas obras de la ingeniería política y de la expresión de la xenofobia y el rechazo pueden separar discriminatoriamente un grupo para establecer el poder de otro grupo sin el consentimiento de los organismos internacionales. La ONU, la Corte Internacional de la Haya y otros organismos no logran hacer nada frente a este fenómeno cada vez más notorio. La única voz que queda opuesta a lo que sucede es de la opinión pública que denuncia la llegada de la era de un nuevo apartheid mundial y de injusticia.

Un recorrido por los lugares donde se encuentran los nuevos viejos muros lleva a distintos rincones del planeta y no hay continente que se salva de esta peste: está el muro y la cerca fronteriza entre los Estados Unidos y México, el muro de Israel separando Cisjordania y la Franja de Gaza, el muro marroquí de arena en Sahara Occidental, un muro en Bagdad recientemente hecho entre barios de sunitas y chiítas, el viejo muro de Belfast en Irlanda del Norte, una valla alta y alambrada con púas en Ceuta y Melilla
Muros y vallas contra la sociedad de bienestar

Aneta de la Mar Ikonómova 
en la entrada de la Unión Europea, el muro y las cercas en Cachemira, los muros en Sudáfrica, Mozambique, Botsuana y Zimbabue, muro entre Uzbekistán y Kirguistán, el muro entre las dos Coreas, etc. Vivimos en un mundo donde la moda de los muros ya marca el paisaje urbano y rural, las casas, los barrios residenciales, las zonas especiales, hasta hay ciudades cada vez más acercadas para no permitir la libre circulación de la gente no deseada. La vida de bienestar es cada vez más un privilegio para pocos y no un derecho de todos los ciudadanos y nacionales.

Hay una enorme variedad de muros, dependiendo de la región, de las necesidades, del financiamiento y de los propósitos que cumplen. Por lo tanto, unos están bien fortificados - hechos de hierro, ladrillo y acero -; otros, de bolsas de arena; terceros son alambrados y trinchados, tienen cámaras sensores y todos los aparatos más sofisticados de la técnica contemporánea; cuartos son vallas alambradas con púas. Hay muros, cercas y vallas electrificados. Los muros se vuelven organismos sofisticados que incluyen personal especializado que vigila rigurosamente la entrada de los que son rechazados como los "otros", los no deseados. Hay muros bien visibles, pero igualmente tantos otros invisibles, en nuestra vida contemporánea.

La pregunta es ¿si todos estos muros en realidad son "muros"? Llámense como se llamen, los muros, las barreras, las vallas, las cercas con púas o sólo con tableros de prohibición de la entrada y la circulación, todos están situados en el espacio que compartimos como ciudadanos y nacionales, vislumbrando la existencia de un nuevo fenómeno: "la lógica de la vida amurallada". En esta lista de muros caben igualmente los que se encuentran en el espacio cibernético - en Internet. Ya somos testigos de cómo se restringen sitios electrónicos considerados peligrosos, prohibidos, no recomendados por alguna u otra razón impuesta más allá de los derechos de los ciudadanos.

Las siguientes tres premisas son los puntos de partida en la conceptualización del fenómeno de los muros contemporáneos para este texto:

1. Hablar de los muros es una manera de hablar de la función discriminatoria social, política, étnica y cultural de las fronteras. Étienne Balibar afirma que en un mundo donde hay más intercambio económico y comunicación y el cual tiende a ser ampliamente unificado, este mundo "tiene más que nunca necesidad de fronteras para repartir, al menos por tendencia, la riqueza y la pobreza en unas zonas territoriales distintas" (Balibar 2003: 181). Por lo tanto, las fronteras se han convertido en instituciones esenciales para constituciones sociales utilizando para este fin el criterio del pasaporte o del carné de identidad. Pero los muros no unen, sino cumplen la función de exaltar el sentido discriminatorio de las fronteras, visualizando un mundo de apartheid mundial. El Estado nacional moderno, considerado como democrático y social, exige de sus ciudadanos definirse nacionalmente, sin embrago, al mismo tiempo, no garantiza sus derechos sociales cuando se cruza espacio transnacional, siempre y cuando se trata de grupos discriminados, desfavorecidos o estigmatizados. 
2. Ningún muro ha resuelto un problema conflictivo de carácter nacional, separatista y fronterizo; tampoco, los problemas de migración, de xenofobia, de prejuicios étnicos, religiosos y culturales. Los muros exaltan los problemas allí donde se construyen, al volver más visible justamente lo que no está resuelto. $\mathrm{Al}$ ofrecer sus espacios como pantallas gigantescas amuralladas visibles para todos, allí cabe el mensaje que estos muros transmiten: "como no podemos y no queremos resolver los problemas de otra manera, construimos este muro para escondernos detrás de él”. El muro es una solución policiaca y militar de un problema de carácter muy profundo, de índole social, política y hasta psicológica.

3. Los muros se construyen frente a las miradas de todos los ciudadanos de este mundo, de los habitantes de un país, de los que viven en una región, ciudad o comunidad. Los muros se ven desde los dos lados, pero siempre hay un lado que es el privilegiado. La opinión pública unas veces pasa por alto estos muros, otras, trata de aprobar su existencia y convencer la comunidad qué útiles pueden ser, también sucede que esta opinión enérgicamente rechaza la presencia y la función de los muros. Todo depende del contexto político y desde dónde se observa el muro, también, cómo se valora su significado y se conjuga su importancia dentro de otros asuntos pendientes de la sociedad y del Estado. Pero el gran problema hoy en día es que, no importa de qué lado están los que se oponen contra los muros o los que los pasan por alto, ni siquiera las Naciones Unidas, la Corte Internacional de Justicia y el resto de los organismos internacionales pueden parar, prohibir, destruir y disminuir el afán de que se hagan nuevos muros y se acaben los viejos.

\section{Segunda imagen: el gran muro del continente americano}

El muro fronterizo entre Estados Unidos y México es una muralla física construida por Estados Unidos en su frontera con México. Su objetivo principal es impedir la entrada de inmigrantes procedentes de la frontera sur hacia territorio estadounidense. La línea fronteriza entre los dos Estados tiene una extensión de 3.141 kilómetros, desde el Golfo de México hasta el Océano Pacífico, no obstante, el muro está elevado sólo en ciertas partes de la frontera. La construcción se inició en 1994 bajo el programa de lucha contra la inmigración ilegal (“Operación Guardián”). En la extensión entre las ciudades Tijuana y San Diego y sus alrededores el muro está compuesto por tres bardas de contención, iluminación de muy alta intensidad, detectores de movimiento, sensores electrónicos y equipos de visión nocturna conectados a la policía fronteriza estadounidense (Border Patrol), así como vigilancia permanente con camionetas todo-terreno, helicópteros artillados, etc. Otros tramos del muro se han hecho en los estados de Arizona, Nuevo México y Texas.
Muros y vallas contra la sociedad de bienestar

Aneta de la Mar Ikonómova 
En Estados Unidos, durante el transcurso de los últimos diez años, se abrió un gran debate sobre la eficacia y la necesidad de la construcción de este muro. Aquí voy a dar sólo algunos argumentos esenciales de los que no están de acuerdo con el muro. Según Charles Bowden, periodista de la región fronteriza en Arizona, en su artículo Nuestro muro en "National Geographic" de mayo de 2007, "El muro parecería violar este profundo sentido de identidad que valora la mayoría de los estadounidenses. Nos consideramos una nación de inmigrantes con nuestra propia Diosa, la Estatua de la Libertad.... Hablar de los Estados Unidos como una nación que se fundó de emigrantes y después rechazar este origen para elaborar una política de migración es una manera de obstaculizar la reflexión de la misma nación sobre su pasado, presente y futuro. Más adelante en su artículo, el autor afirma: "A veces, los muros se construyen para evitar que la gente escape, pero casi todos se erigen para mantener la gente fuera". La conclusión del periodista es: "todos se dan cuenta de que el muro es una solución policíaca a un problema económico."

Hoy, después de varios años de asesinatos y muertes no deseados en la frontera entre Estados Unidos y México, se puede decir que no sólo se trata de un problema económico que marca la frontera y el muro, sino también de asuntos profundamente arraigados con el tráfico de armas y droga. En los últimos seis años se produjo una crisis de la seguridad en México, especialmente en los estados fronterizos con los Estados Unidos, justamente por esta razón. No es secreto para nadie hoy en día que varios emigrantes mueren cruzando la frontera como víctimas de tiroteos cruzados de las bandas que se disputan el dominio del tráfico que se dirige hacia norte. Por eso, está la pregunta: ¿quiénes son los verdaderos ilegales? ¿los que buscan trabajo en los Estados Unidos indocumentados o los que trafican con armas y droga en la frontera?

Según la Federación Internacional de los Derechos Humanos (FIDH) "la gran vulnerabilidad de la población migrante indocumentada, vulnerabilidad debida a su condición de extranjero y muchas veces de víctima de la trata de personas y del tráfico de seres humanos, es particularmente evidente [...] en la frontera sur de Estados Unidos (frontera con México) (FIDH 2008)." Si se compara el Muro de Berlín con éste entre Estados Unidos y México, se ve que más de 4 mil migrantes han muerto atravesando el muro americano entre los años 1996 y 2008, o sea, 15 veces más que el número de personas muertas atravesando el muro de Berlín en sus 28 años de existencia (FIDH 2008: 7).

"Está claro que las restricciones sobre la libre circulación de personas contradicen el espíritu de la globalización”, afirman Antoine Pécoud y Paul de Guchteneire (2005: 2). Las fronteras frenaban todo - dinero, bienes, personas -, pero hoy día paran más a las personas. La situación de México-Estados Unidos es el mejor ejemplo de esa paradoja: dos países unidos en un tratado de libre comercio están separados por una frontera militarizada. La Declaración 
Universal de los Derechos Humanos establece que "toda persona tiene derecho a salir de cualquier país, incluso el propio, y a regresar a su país" (artículo 13-2). Es cierto que la mayoría de las personas son libres de salir de su país, pero sólo una minoría tiene derecho a entrar en otro país" (Pécoud y de Guchteneire 2005: 2).

El muro entre los Estados Unidos y México está construido sobre una frontera que se ha vuelto fuertemente asimétrica con los años. Por lo tanto, sucede que la migración, la cual se reconoce como un derecho humano en un mundo donde hay cada vez más circulación de los ciudadanos de los países desarrollados, es restringida y rechazada como derecho para los trabajadores mexicanos no calificados. Ellos han quedado fuera del acuerdo NAFTA (1994) que sólo se ha interesado por la mano de obra calificada e intereses comerciales. Pero la relación directa entre esta política restrictiva, discriminatoria de los Estados Unidos y la actualidad quedan plasmadas en la aprobación de la Ley de Arizona SB1070, conocida como "Ley del odio", que entró en vigencia en septiembre de 2012. La ley funciona como una extensión del muro físico que ahora puede frenar la migración indocumentada de una manera directamente racista - los víctimas de esta ley son todos ciudadanos con rasgos latinos $u$ otros que pueden ser detenidos por sospecha de que son indocumentados.

\section{Tercera imagen: el nuevo muro de Berlín es el muro de Israel}

El más fortificado muro actualmente no es éste de los Estados Unidos, sino de Israel. Las autoridades israelitas dicen que han hecho una barrera de seguridad necesaria, pero este muro sofisticado que se eleva en Cisjordania y la Franja de Gaza desde 2002 es mucho más que un muro fronterizo.

"El muro se adentra bastante en Cisjordania - una sección penetra $14 \mathrm{~km}$ en territorio palestino - para envolver la extensa red de asentamientos israelíes y sus áreas planificadas para expansión. Cincuenta y seis asentamientos judíos - hogar de más de 170000 colonos - estarán entre el muro y la Línea Verde. Cuando se toman en cuenta los asentamientos judíos adicionales en el este de Jerusalén, tres cuartas partes de los 425000 colonos estarán viviendo detrás del muro. Si se implementan los planes actuales, el muro anexará el 10\% del territorio de Cisjordania”, dice Tim Morris en publicación de ACNUR (Morris 2012). Por su parte, la Corte Internacional de Justicia declaró ilegal el Muro y todas sus instalaciones; igualmente la ONU ha hecho varias declaraciones para impedir su construcción. Pero ¿quién va a parar la iniciativa israelí si en realidad ninguna organización internacional o gobierno se puede oponer contundentemente a la política de agresión de Estado israelí actual?
Muros y vallas contra la sociedad de bienestar

Aneta de la Mar Ikonómova 
Cuarta imagen: un muro en el desierto y el muro de la Unión Europea

En el desierto de Sahara en África está el muro más largo - de unos 2700 kilómetros. En realidad, se trata de un sistema de ocho muros de seguridad con varios búnquers, vallas y campos de minas. El muro fue elevado en los años ochenta del siglo pasado con el propósito de parar los ataques de Frente Polisario y así frenar la lucha del pueblo saharaui en defensa de su derecho a tener propio Estado y no vivir bajo el mandato marroquí. Aunque es un muro muy agresivo, la lucha del pueblo saharaui no se ha detenido. Al revés, cada vez la opinión pública apoya más la causa saharaui - el derecho de tener un Estado soberano fuera del poder marroquí.

La Unión europea también tiene su muro, pero no en el territorio europeo, sino en África. España ha levantado tres vallas en las fronteras de sus ciudades africanas, Ceuta y Melilla, con el fin de impedir el ingreso de indocumentados que utilizan dichos territorios para penetrar en la Unión. No obstante, el problema de ingreso indocumentado de mano de obra barata que se dirige a la Unión Europea, que la necesita, no está resuelto.

¿Será la Unión Europea una "fortaleza medieval" que trata de alejar a los bárbaros de sus murallas, o encontrará, por fin, una política de respeto a los ciudadanos temporales que trabajan en su territorio y tienen derechos? Por ahora, sólo se ha visto un incremento de los métodos policíacos de vigilar las fronteras, pero no una solución integral y justa.

"En Europa se levantan muros cada vez más altos, en Ceuta y Melilla, últimos baluartes de la civilización, esos muros y alambradas señalan los límites de las promesas portadas por esa misma civilización, aquellas que hablaban de integración, de equidad, de justicia pero que terminan construyendo las líneas cada vez más visibles del prejuicio, la marginalización y el desconocimiento." dice Ricardo Forster, filósofo y ensayista argentino. (Forster 2012).

\section{Quinta imagen: los muros de los nacionalismos en Belfast y en Chipre}

Aunque en Irlanda del Norte sigue avanzando el proceso de paz y ya existe un cese de fuego, todavía los visitantes de Belfast pueden recurrir a la calle donde se eleva un muro entre los vecinos que pertenecen a las dos comunidades irlandesas opuestas durante los años: de los católicos y de los protestantes. Los niños de estas dos comunidades estudian en distintos colegios y tratan de no frecuentarse en las calles todavía. ¿Hasta cuándo este muro guardará la memoria de una guerra y el odio de los nacionalismos antagónicos que dejaron muertos y familias destruidas? ¿Cómo se sanan las heridas de los conflictos nacionales si todavía están presentes los muros que los simbolizan? 
Es una buena noticia que hace unos años ya no está el muro que dividía los turcochipriotas de los grecochipriotas en Nicosia. No obstante, Chipre todavía sigue dividido: por un lado están los ciudadanos que forman parte de la Unión Europea, los de la comunidad grecochipriota, y por otro lado, los que pertenecen a la comunidad turcochipriota y no han logrado formar un Estado común con sus vecinos que no los aceptan. En el mapa de la Unión Europea, Chipre está presentado siempre como un territorio entero que de esta manera entró a formar parte de la Unión en 2004. No obstante, en la práctica unos ciudadanos tienen pasaportes europeos y el resto, no. El muro no está, pero está viva su herencia.

\section{Sexta imagen: los futuros muros}

Rusia ha anunciado su intención de construir un muro en la frontera con Chechenia. ¿Es posible parar o convencer el gobierno ruso de que no haga este muro contra los chechenos acusados de ser el peor enemigo terrorista de $\mathrm{Ru}$ sia? Hoy en día la acusación de terrorismo es una buena excusa para silenciar gran variedad de realidades e historias poco conocidas y que se refieren a pueblos y grupos identidarios que llevan conflictos armados bien complejos. Los muros nunca han resuelto un conflicto nacional, tampoco han sido obstáculo que pare los verdaderos terroristas.

Para Ulrich Beck "la globalización ha derrumbado la idea de vivir y actuar en los espacios cerrados y recíprocamente delimitados de los Estados nacionales y de sus respectivas sociedades nacionales" (Beck 1998). Los estudios tradicionales sobre fronteras se han centrado en la localización física del límite y en su función protectora de la soberanía del Estado (Bradshaw y Linarez de Gomez 1999: 14-19). Estos estudios se han conducido dentro de la tradición del imaginario del Estado-nación definido en el tratado de Westfalia en 1648. Desde esta visión del Estado, la frontera se ha concebido como el área limítrofe del territorio nacional hasta donde el Estado ejerce su soberanía. La frontera es entendida como la expresión o manifestación del límite de la territorialidad del Estado. Pero hoy es cada vez más obvio que las fronteras ya no pueden ser concebidas como fortalezas, a pesar de la neurótica vigilancia que ejercen sobre ellas las fuerzas armadas de cada país. En la política comercial exterior, las fronteras funcionan como esclusas que permiten la entrada y salida de capitales. No obstante, el problema de las fronteras no es con los flujos comerciales, sino con los flujos poblacionales y más que todo con sus parámetros de identidad (Emmerich 2006).

La frontera es el otro rostro de la globalización, su alter ego, la verdad de sus promesas, el punto exacto en el que pasan las mercancías y los flujos de dinero y se quedan las personas. La frontera es una línea en la que la pobreza y la oscuridad de la piel constituyen el límite, la marca de la sospecha. Aque- 
llo que la ideología del libre mercado propaga a través de todo el planeta, aquello que habla de la libertad, de la apertura de fronteras, de la libre circulación de productos, se cierra brutalmente sobre el cuerpo del extranjero, del inmigrante ilegal, del desesperado que intenta huir de la miseria y va en pos de una promesa que encuentra su paredón en esos muros que cierran el paso, en esas alambradas de púas que recuerdan otro tiempo europeo y que destacan el otro rostro de la civilización que se autocomplace en su herencia ilustrada y democrática (Forster 2012).

\section{Séptima imagen: quitar las cercas para trabajar las tierras}

A primera vista, los problemas de los muros y de las fronteras nacionales no tienen nada que ver con el movimiento de los "Sin tierra" en Brasil y con otros movimientos sociales parecidos en África y Asia (Bhumi Uchhed Pratirodh Committee en la India, Landless Peoples Movement en Sudáfrica y otros). El Movimiento de los Trabajadores Sin Tierra surgió en Brasil en los inicios de los años 80 del siglo pasado como una respuesta a la necesidad de los campesinos y los desocupados que no tenían ni tierra ni trabajo, pero querían encontrar una manera digna de vivir en el campo y trabajar las tierras que han quedado abandonadas. En Brasil, un país continente, donde hay haciendas que superan los territorios de algunos Estados europeos, la mitad de la tierra está centrada en las manos de los latifundistas, así que casi el 50\% de la tierra pertenece a sólo $1 \%$ de la población. Al organizar la toma de las tierras vacías, no trabajadas por los latifundistas, los campesinos dieron inicio al "Movimiento Sin tierra". De tal modo, estas personas pobres que tenía hasta ese momento sólo una opción - de irse a las ciudades para formar parte de las favelas y buscar trabajo, pero nunca encontrarlo como campesinos propietarios -, hicieron un proceso inverso de lo que sucedió en Inglaterra en el siglo XVIII.

¿Qué sucedió en la isla británica en aquel siglo XVII? Con el término cercamiento ('enclosure' en inglés) se define al cierre de los terrenos comunales a favor de los terratenientes que ocurrió en Inglaterra durante los siglos XVIII y XIX. Fueron tres etapas: la apropiación por los propietarios de espacios previamente dedicados al uso colectivo, la sustitución del antiguo sistema abierto por campos cerrados y establecimiento de vastos dominios alquilados a campesinos empobrecidos sin medios financieros. En los estudios de los economistas, estos cercamientos fueron considerados como una supuesta "revolución" de los ricos contra los pobres. Lo que sucedía era que los nobles subvertían el orden social al no respetar las antiguas leyes y costumbres, y recurrían a la violencia, la presión, hasta la intimidación, para lograr expulsar sus vecinos de los bienes comunes, derribar sus casas y después tomar la gente como mano de obra barata que tiene la necesidad de trabajar para los grandes propietarios (Boyle 2003). 
"Vemos, en efecto, a los nobles y los ricos en todos los lugres del reino donde se cría la lana más fina y más cara [...] no dejan tierras para cultivo: lo cercan todo para el pastoreo, tiran abajo las casas, destruyen poblados, no dejan nada en pie excepto la iglesia, que dedican a establo" dice textualmente Tomás Moro en su Utopia (citado, Boyle 2003). En consecuencia de este proceso conocido como "cercamiento masivo", los pequeños arrendatarios se convirtieron en peones endeudados, trabajadores temporarios. Otras veces, terminaron como mendigos y ladrones, según Tomás Moro.

En los estudios históricos y económicos hace unas décadas se enfatizaban los resultados beneficiosos del cercamiento y se consideraba este proceso como un verdadero progreso capitalista que puso las bases de la sociedad moderna. Sin embargo, hoy en día en trabajos empíricos más recientes se ha demostrado que, de haber tenido alguno, los efectos en el aumento de la producción agrícola no fueron tan grandes (Boyle 2003). El efecto más importante de este cambio que se dio en Inglaterra es que con las cercas se delimitaban las tierras de la propiedad privada y se imponía la regla de esta dominación como única.

Volvamos al movimiento social de "Sin Tierras". Bajar las cercas y tomar las tierras de los grandes latifundios para trabajarlas, muchas veces en cooperativas o simplemente con apoyo de los vecinos, éste es el camino que se ha tomado - en dirección opuesta de lo que ocurrió hace tres siglos. Las tierras vuelven a ser parte de la estructura de trabajo en la cual lo importante no es delimitar la propiedad y buscar sólo provecho individual, sino lograr gracias al trabajo comunal la sobrevivencia de los pequeños campesinos que no pueden competir con los grandes agricultores en un sistema cada vez más globalizado.

Bajar las cercas, tomar las tierras, exigir que el Estado intervenga jurídicamente y autorice las tierras para los nuevos dueños es una real revolución agraria. Las cercas, las vallas, los muros, las barreras son superadas con propósito de construir una vida digna para todos cultivadores de las tierras, para todos los ciudadanos que quieren hacer una sociedad justa. Sólo así la sociedad de bienestar puede garantizar el derecho de trabajo y no empujar a la gente en convertirse en mano de obra barata para las grandes urbes o irse como emigrantes indocumentados a otros países.

La globalización termina allí donde inició - en la posibilidad de hacer un mundo más comunicado y relacionado entre sí, más desarrollado tecnológicamente, pero no tan exclusivo y discriminatorio. "El bien común" vuelve a tomar sentido en el fin del túnel de la imposición de una globalización muy poco equitativa.

\section{Bibliografía}

Balibar E. (2003), Fronteras del mundo, fronteras de la política, en: Nosotros, ¿Ciudadanos de Europa?: las fronteras, el Estado, el pueblo, Editoral Tecnos, Madrid.

Beck U. (1998), ¿Qué es la globalización?, Editorial Paidós, Madrid. 
Bowden Ch. (2007), Nuestro muro, "National Geographic", en español, mayo, pp. 2-26.

Boyle J. (2003), El segundo movimiento de cercamiento y la construcción del dominio público, disponible en: http://www.elastico.net/copyfight/upload/el_segundo_movimiento_de_ cercamiento.pdf, consulta: 29.10.2012.

Bradshaw R., Linarez de Gomez R. (1999), Fronteras: una visión teórica en el período contemporáneo, "Aldea Mundo", año 4, no 7, mayo-octubre, pp. 14-19.

Departamento de Economía de Instituto Tecnológico y de Estudios Superiores de Monterrey, México. Programa de Desarrollo Regional Frontera Norte 2001-2006, disponible en: http://www.mty.itesm.mx/daf/deptos/ec/ci/main.htm, consulta: 10.09.2012.

Chacón J. A. (2006), No one is illegal: Fighting Racism and State Violence on the U.S. Mexico border, Haymarket, Chicago.

Emmerich N. (2006), Fronteras, muros y límites en la globalización, Documento de trabajo, Julio, Departamento de Investigaciones, Universidad de Belgrano, Buenos Aires, disponible en: http://es.scribd.com/doc/20115446/Fronteras-muros-y-limites-en-la-globalizacion, consulta: 30.10.2012.

FIDH (2008), Federación Internacional de los Derechos Humanos, Estados Unidos-México Muros, Abusos y Muertos en las fronteras. Violaciones flagrantes de los derechos de los migrantes indocumentados en camino a Estados Unidos, Marzo, no 488/3, disponible en: http://www. womenontheborder.org/documents/USAMexiquemigran488esp.pdf., consulta: 30.10.2012.

Forster R. (2012), La frontera, "Rayando los confines", disponible en: http://www. rayandolosconfines.com.ar/variacion_frontera.html, consulta: 30.10.2012.

Gras Balaguer M., Martinell E., Torres A. (2002), (eds.), Fronteras: lenguas, cultura e identidad, Institut Català de Cooperación Iberoamericana, Barcelona, pp. 248 - 263.

Ortega A. (2006), Los muros de la globalización, "Foreign Policy" en español, 1 de febrero, disponible en: http://www.fp-es.org/los-muros-de-la-globalizacion, consulta: 30.10.2012.

Pécoud A., De Guchteneire P. (2005), Migración sin fronteras: una investigación sobre la libre circulación de personas, Unesco.

Restivo N. (2006), Los muros de la globalización ya dividen a veintisiete países, "Clarín", 9 de abril, disponible en: http://edant.clarin.com/diario/2006/04/09/elmundo/i-02801.htm, consulta: 30.10 .2012 .

Morris T. (2012), ¿Sólo un Muro?, “Publicaciones de ACNUR”, disponible en: http://www. acnur.org/biblioteca/pdf/4956.pdf, consulta: 1.09.2012. 